American Journal of Applied Sciences 7 (2): 214-220, 2010

ISSN 1546-9239

(C) 2010 Science Publications

\title{
New Mesogenic Schiff Base Esters with Polar Chloro Substituent: Synthesis, Thermotropic Properties and X-Ray Diffraction Studies
}

\author{
${ }^{1}$ Sie-Tiong Ha, ${ }^{2}$ Lay-Khoon Ong, ${ }^{3}$ Yasodha Sivasothy, ${ }^{4}$ Guan-Yeow Yeap, \\ ${ }^{4}$ Peng-Lim Boey and ${ }^{5}$ Hong-Cheu Lin \\ ${ }^{1}$ Department of Chemical Science, Faculty of Science, University Tunku Abdul Rahman, \\ Jln University, Bandar Barat, 31900 Kampar, Perak, Malaysia \\ ${ }^{2}$ Department of Science, Faculty of Engineering and Science, University Tunku Abdul Rahman, \\ Jln Genting Klang, Setapak, 53300 Kuala Lumpur, Malaysia \\ ${ }^{3}$ Department of Chemistry, Faculty of Science, University Malaya, 50603 Kuala Lumpur, Malaysia \\ ${ }^{4}$ Liquid Crystal Research Laboratory, School of Chemical Science, University Sains Malaysia, 11800 \\ Minden, Penang, Malaysia \\ ${ }^{5}$ Department of Material Science and Engineering, National Chiao-Tung University, \\ 1001 Ta-Hsueh Road, Hsinchu 300, Taiwan, ROC
}

\begin{abstract}
Problem statement: Many studies have been conducted on the Schiff base's alkyl and alkyloxy possessing terminal halogen substituent. However, the thermotropic properties of Schiff base's ester (or alkanoyloxy) with chloro terminal group remained unstudied. Approach: Synthesis a series of new Schiff base ester possessing polar chloro group and investigate its mesomorphic properties. The title compounds were prepared via condensation and esterification reactions. The molecular structures were confirmed using spectroscopic techniques. All the members are differed by the length of alkanoyloxy chain, $\mathrm{C}_{\mathrm{n}-1} \mathrm{H}_{2 \mathrm{n}-1} \mathrm{COO}$, where $\mathrm{n}=2-8,10,12,14,16$ and 18. The mesomorphic properties were studied using differential scanning calorimetry, polarizing optical microscopy and temperature-dependent X-ray diffractometry. Results: Whilst short members $(n=2-5)$ were not mesogenic compounds, n-hexanoyloxy and n-heptanoyloxy derivatives exhibited monotropic $\mathrm{SmA}$ and SmB phases. Enantiotropic smectogenic A and monotropic smectogenic B were observed in n-octanoyloxy to n-hexadecanoyloxy derivatives. Highest member of the series, n-octadecanoyloxy derivatives exhibited monotropic SmA phase. Conclusion: The ester linkage and polar terminal group in the present series are essential for the formation of liquid crystal phase in Schiff bases.
\end{abstract}

Key words: Azomethine, liquid crystal, smectic A, smectic B, X-ray diffraction

\section{INTRODUCTION}

With development of liquid crystal science and technology, more mesogens have been prepared and studied. Thermotropic liquid crystal is one of type of mesogens currently extensively studied (Yuksel et al., 2007; Zhang et al., 2005). Most thermotropic liquid crystals are rod-like molecules having a rigid core composed of two or more aromatic rings and one or more flexible terminal chains. Schiff base, also known as imine $(\mathrm{CH}=\mathrm{N})$, is a linking group used to connect between core groups. It provides a stepped core structure but still maintained the molecular linearity in order to exhibit higher stability and form mesophases
(Collings and Hird, 1997; Singh and Dunmur, 2002). Extensive studies on Schiff base core system had been conducted ever since discovery of MBBA showing nematic phase at room temperature (Kelker and Scheurle, 1969). Nowadays, a lot of studies have been conducted on the Schiff base possessing ester chain or called Schiff base esters owing to their interesting properties and considerable temperature range (Ha et al., 2009a; 2009b; Yeap et al., 2004; 2006a; 2006b; 2006c).

One of the typical terminal moiety exhibiting liquid crystal properties is those with terminal electronegative moiety, such as halogen groups. Terminal halogens (F, $\mathrm{Cl}, \mathrm{Br}$ and I) are polar substituents possess strong

Corresponding Author: Sie-Tiong Ha, Department of Chemical Science, Faculty of Science, University Tunku Abdul Rahman, Jln University, Bandar Barat, 31900 Kampar, Perak, Malaysia Fax: +6054661676 
dipole moments which promote mesomorphic properties (Galewski, 1994; Galewski and Coles, 1999; Sakagami and Nakamizo, 1980). The increased dipole moment can enhance the stability of lattice and melting temperatures (Singh and Dunmur, 2002). Chlorine atom is a terminal substituent which its polarisability and size lies between fluorine and bromine atoms (Yeap et al., 2004). It was observed that as the ionic radius of terminal substituent increasing, the molecules tend to orientate in parallel arrangement (Dave and Menon, 2000). Thus, smectic polymorphism is not unusual for chloro terminal substituent and has been frequently observed as the alkyl or alkoxy length increased (Galewski and Coles, 1999; Petrov et al., 2001).

In this continuation studies, Schiff base ester and chlorine terminal moieties are incorporated into a new series of homologous compounds, 4-chlorobenzylidene4'-n-alkanoyloxyanilnes, nClBA. FT-IR, ${ }^{1} \mathrm{H}$ and ${ }^{13} \mathrm{C}$ NMR, EI-MS and elemental analysis were employed to elucidate the molecular structure of the title compounds whereas the liquid crystal behaviors were determined by DSC, POM and XRD analysis. The mesomorphic behaviors of homologous compounds are rationalized based on the changing of alkyl length chain.

\section{MATERIALS AND METHODS}

Materials: 4-Aminophenol, 4-chlorobenzaldehyde, 4dimethylaminopyridine, acetic acid, butyric acid, hexanoic acid, heptanoic acid, decanoic acid, dodecanoic acid, tetradecanoic acid, hexadecanoic acid and octadecanoic acid were obtained from Merck (Germany) without further purification. Propionic acid, pentanoic acid, octanoic acid and N,Ndicyclohexylcarboiimide were acquired from Acros Organics (USA).

Techniques: Electron Impact-Mass Spectrum (EI-MS) was recorded by a Finnigan MAT95XL-T mass spectrometer operating at $70 \mathrm{eV}$ ionizing energy. Microanalyses were carried out on Perkin Elmer 2400 LS Series CHNS/O analyser. FT-IR data were acquired on Perkin Elmer 2000-FTIR spectrophotometer in the frequency range of $4000-400 \mathrm{~cm}^{-1}$ with samples embedded in $\mathrm{KBr}$ discs. ${ }^{1} \mathrm{H}$ and ${ }^{13} \mathrm{C}$ NMR spectra were recorded in $\mathrm{CDCl}_{3}$ by utilizing JEOL $400 \mathrm{MHz}$ NMR Spectrometer with TMS as internal standard. The phase transition temperatures were measured by Mettler Toledo DSC823 Differential Scanning Calorimeter (DSC) at a scanning rate of $10^{\circ} \mathrm{C} \mathrm{min}^{-1}$. Liquid crystalline properties were investigated by Polarizing Optical Microscopy (POM) using a Carl Zeiss
Polarizing Optical Microscope (POM) attached to a Linkam Hotstage.

Synchrotron powder X-Ray Diffraction (XRD) measurements were performed at beamline BL17A where the X-ray wavelength used was $1.32633 \AA$. XRD data were collected using Imaging Plates (IP, of an area $=20 \times 40 \mathrm{~cm}^{2}$ and a pixel resolution of 100) curved with a radius equivalent to the sample-to-image plate distance of $280 \mathrm{~mm}$ and the diffraction signals were accumulated for $3 \mathrm{~min}$. The powder samples were packed into a capillary tube and heated by a heat gun, where the temperature controller was programmed by a PC with a PID feedback system. The scattering angle theta was calibrated by a mixture of silver behenate and silicon.

Synthesis: The synthesis route of the title compound is shown in Fig. 1.

Synthesis of 4-Chlorobenzylidene-4'-hydroxyaniline, CIBHA: An equivalent amount $(10 \mathrm{mmol})$ of 4aminophenol and 4-chlorobenzaldehyde, along with three drops acetic acid were mixed and reacted in 30 $\mathrm{mL}$ of ethanol under heat reflux for three hours. The mixture was cooled down to room temperature and filtered. The yellow product was washed with cold ethanol.

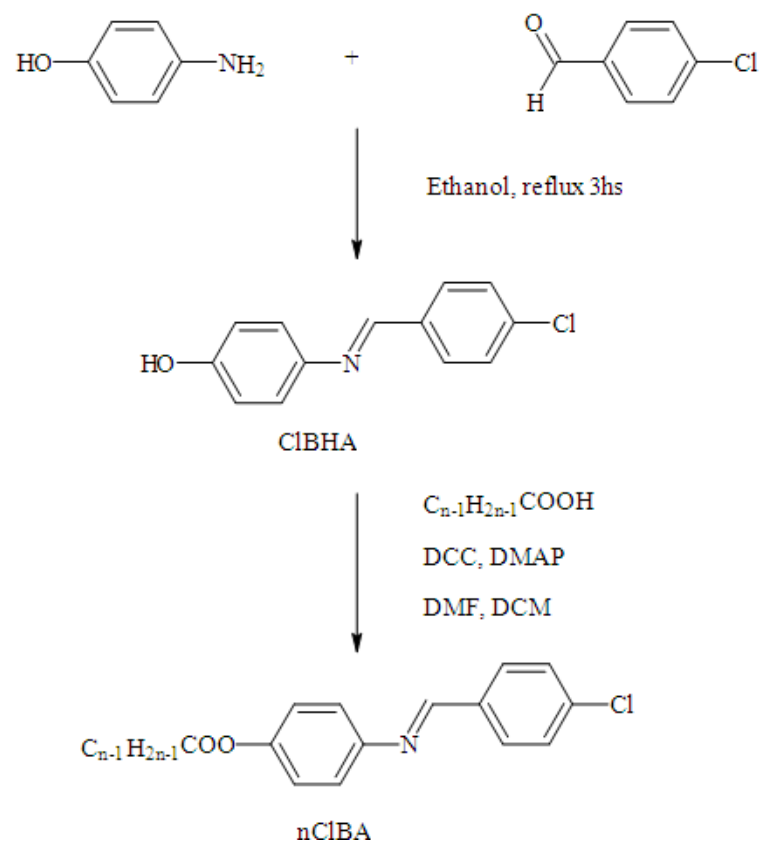

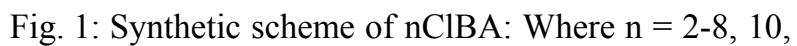
$12,14,16$ and 18 
Am. J. Applied Sci., 7 (2): 214-220, 2010

Synthesis of 4-Chlorobenzylidene-4'alkanoyloxyaniline, nClBA: First, ClBHA ( $2 \mathrm{mmol}$ ) dissolved in minimum amount of DMF was added into a mixture of fatty acid $(2 \mathrm{mmol})$ and DMAP $(0.2 \mathrm{mmol})$ which has been dissolved in dichloromethane $(20 \mathrm{~mL})$. DCC $(2 \mathrm{mmol})$ in dichloromethane $(5 \mathrm{~mL})$ was added dropwise into the mixture while stirring at $0^{\circ} \mathrm{C}$ for an hour, then continue stirring at room temperature for $3 \mathrm{~h}$ (Ha et al., 2009b; Yeap et al., 2004). Finally, the mixture was filtered and excess solvent was removed from filtrate by evaporation. The white product was recrystallized with ethanol until the transition temperature remained constant. The percentage of yield and analytical data of the title compounds are tabulated in Table 1.

EI-MS, IR, ${ }^{1} \mathrm{H}$ and ${ }^{13} \mathrm{C}$ NMR data of representative compound 16ClBA is given as follow:

16ClBA: EI-MS ( $\mathrm{m} / \mathrm{z}$, relative intensity): 231.1, (100); 469.4, (10); IR (KBr) $\left(\mathrm{cm}^{-1}\right): 2917,2849$ $\left(\mathrm{CH}_{2}\right.$ stretching), $1752(\mathrm{C}=\mathrm{O}), 1624(\mathrm{C}=\mathrm{N})$, 1498, $1472(\mathrm{C}=\mathrm{C}$ aromatic $), 1207(\mathrm{C}-\mathrm{O}) ;{ }^{1} \mathrm{H}$ NMR (400 MHz, $\left.\mathrm{CDCl}_{3}\right): \delta /$ ppm: 0.87-0.94 (t, $\left.3 \mathrm{H}, \mathrm{J}=13.3 \mathrm{~Hz}, \mathrm{CH}_{3}-\right), 1.21-1.48\left(\mathrm{~m}, 26 \mathrm{H}, \mathrm{CH}_{3}-\right.$ $\left.\left(\mathrm{CH}_{2}\right)_{13}-\right), \quad 1.73-1.82 \quad(\mathrm{q}, \quad 2 \mathrm{H}, \quad \mathrm{J}=55.02 \mathrm{~Hz},-$ $\mathrm{CH}_{2} \mathrm{CH}_{2} \mathrm{COO}-$ ), $2.56-2.64$ (t, $2 \mathrm{H}, \mathrm{J}=15.03 \mathrm{~Hz}$,$\mathrm{CH}_{2} \mathrm{CH}_{2} \mathrm{COO}-$ ), 7.10-7.15 (d, $2 \mathrm{H}, \mathrm{J}=8.7 \mathrm{~Hz}$, Ar-H), 7.22-7.49 (d, 2H, J = 8.6 Hz, Ar-H), 7.45-7.50 (d, 2H, J = 8.4 Hz, Ar-H), 7.82-7.89 $(\mathrm{d}, 2 \mathrm{H}, \mathrm{J}=8.5 \mathrm{~Hz}, \mathrm{Ar}-\mathrm{H}), 8.41-8.46(\mathrm{~s}, 1 \mathrm{H}$, $\mathrm{C} \underline{\mathrm{H}}=\mathrm{N}) ;{ }^{13} \mathrm{C}$ NMR $\left(100 \mathrm{MHz}, \mathrm{CDCl}_{3}\right), \delta / \mathrm{ppm}$ : $14.62\left(\mathrm{CH}_{3}\right), 23.16,25.39,29.56,30.15,32.38$, 34.82 (for methylene carbons), 122.22, 122.73 , $129.52,130.40,134.94,137.86,149.43,149.52$ (aromatic carbons), $159.39(\mathrm{CH}=\mathrm{N}), 172.95$ (COO)

\section{RESULTS}

Synthesis and spectral studies: Structural elucidation of compounds nClBA was ascertained by using elemental analysis (Table 1), mass spectrometric and spectroscopic methods (FT-IR and NMR).

Mesomorphic properties: The compound showed interesting thermotropic behavior and its melting was carefully observed by POM both in the heating and cooling scans. Optical photomicrographs of $8 \mathrm{ClBA}$ are shown in Fig. 2 as the representative illustration. The POM observations were then verified by DSC measurements (Fig. 3). The transition temperatures, enthalpy changes and phase sequences are summarized in Table 2.
Table 1: Percentage yields and analytical data of nClBA

\begin{tabular}{|c|c|c|c|c|c|}
\hline \multirow[b]{2}{*}{ Compound } & \multirow{2}{*}{$\begin{array}{l}\text { Yield } \\
(\%)\end{array}$} & \multirow[b]{2}{*}{ Formula } & \multicolumn{3}{|c|}{ Percentage of found ( $\%$ Cald.) } \\
\hline & & & $\mathrm{C}$ & $\mathrm{H}$ & $\mathrm{N}$ \\
\hline $2 \mathrm{ClBA}$ & 27 & $\mathrm{C}_{15} \mathrm{H}_{12} \mathrm{ClNO}_{2}$ & 2) & 33( & $\overline{07}$ \\
\hline $3 \mathrm{Cll}$ & 34 & $C$ & 9) & 0) & \\
\hline 4ClBA & 58 & $\mathrm{C}_{17} \mathrm{H}_{16} \mathrm{ClNO}_{2}$ & 6) & 34) & 4.64) \\
\hline $5 \mathrm{Cl}$ & 53 & & & & \\
\hline 6ClBA & 70 & $\mathrm{NO}_{2}$ & 9) & 6.05( & 25) \\
\hline & 49 & $\mathrm{C}_{20} \mathrm{H}_{22} \mathrm{ClNO}_{2}$ & & & 07) \\
\hline & 42 & & & & \\
\hline $10 \mathrm{ClBA}$ & 26 & $\mathrm{O}_{2}$ & 8) & $7.37(7.31)$ & $3.66(3.63)$ \\
\hline $12 \mathrm{C}$ & 73 & $\mathrm{C}_{25} \mathrm{H}_{3}$ & & $7.70(7.79)$ & $3.32(3.38)$ \\
\hline & 41 & & & 8.19 & \\
\hline & 68 & & & 8.54( & $2.95(2.98)$ \\
\hline $18 \mathrm{ClBA}$ & 51 & $\mathrm{C}_{31} \mathrm{H}_{44} \mathrm{ClNO}_{2}$ & $74.82(74.74)$ & $8.88(8.90)$ & $2.80(2.81)$ \\
\hline
\end{tabular}

Table 2: Transition temperatures and associated enthalpy changes of nClBA upon heating and cooling

\begin{tabular}{|c|c|}
\hline Compound & Transition temperatures $\left({ }^{\circ} \mathrm{C}\right)\left(\Delta \mathrm{H}, \mathrm{kJ} \mathrm{mol}^{-1}\right)$ \\
\hline \multirow[t]{2}{*}{$2 \mathrm{ClBA}$} & Cr 136.19(33.68) I \\
\hline & I 105.62(31.20) Cr \\
\hline \multirow[t]{2}{*}{$3 \mathrm{ClBA}$} & Cr $126.10(30.35) \mathrm{I}$ \\
\hline & I 105.37(30.27) Cr \\
\hline \multirow[t]{2}{*}{ 4ClBA } & Cr 108.31(30.14) I \\
\hline & I 83.46(32.27) Cr \\
\hline \multirow[t]{2}{*}{$5 \mathrm{ClBA}$} & Cr $112.08(33.35) \mathrm{I}$ \\
\hline & I 89.52(31.42) Cr \\
\hline \multirow[t]{2}{*}{$6 \mathrm{ClBA}$} & Cr 100.18(33.86) I \\
\hline & I 88.72(5.43) SmA 81.53(3.29) SmB 65.97(21.76) Cr \\
\hline \multirow[t]{2}{*}{ 7ClBA } & Cr 96.80(38.86) I \\
\hline & I 92.09(5.59) SmA 83.43(3.64) SmB 71.73(28.05) Cr \\
\hline \multirow[t]{2}{*}{$8 \mathrm{ClBA}$} & Cr 92.97(38.24) SmA 98.07(6.41) I \\
\hline & I 96.58(6.70) SmA 83.42(3.84) SmB 70.75(32.23) Cr \\
\hline \multirow[t]{2}{*}{ 10ClBA } & $\mathrm{Cr}_{1}$ 93.37(33.50) SmA 101.47 (5.62) I \\
\hline & I 99.81(5.64) SmA 82.23 (2.83) SmB 55.54 (29.64) Cr \\
\hline \multirow[t]{2}{*}{$12 \mathrm{ClBA}$} & Cr 94.65(39.83) SmA 101.28(6.27) I \\
\hline & I 100.33(6.47) SmA 79.85(2.81) SmB 66.91(36.65) Cr \\
\hline \multirow[t]{2}{*}{$14 \mathrm{ClBA}$} & Cr 97.03(43.47) SmA 100.12(5.51) I \\
\hline & I 98.70(6.73) SmA 76.74(2.76) SmB 70.27(42.14) Cr \\
\hline \multirow[t]{2}{*}{ 16ClBA } & $\mathrm{Cr} 92.88(50.60) \mathrm{SmA} 101.00(8.31) \mathrm{I}$ \\
\hline & I 99.27(8.97) SmA 81.99(4.47) SmB 51.02(44.12) Cr \\
\hline \multirow[t]{2}{*}{$18 \mathrm{ClBA}$} & $\mathrm{Cr} 97.67(63.18) \mathrm{I}$ \\
\hline & I 94.11(6.95) SmA 86.08(57.68) $\mathrm{Cr}$ \\
\hline
\end{tabular}

The values in italic were taken during cooling cycle; $\mathrm{Cr}=$ Crystal; $\mathrm{SmA}=$ Smectic A; SmB = Smectic B; I = Isotropic liquid

In order to advance investigate the liquid crystal properties, X-ray diffraction was conducted on representative compound 12ClBA. XRD pattern of representative compound 12ClAB is shown in Fig. 4.

\section{DISCUSSION}

A very good agreement was found between the calculated and found values obtained from elemental analysis of nClBA (where $\mathrm{n}=2-8,10,12,14,16$ and 18) (Table 1). The molecular ion peak at $\mathrm{m} / \mathrm{z}=469.4$ in mass spectrum of representative compound 16ClBA suggested 16ClBA was successfully synthesized owing to the molecular ion peak was corresponding to molecular mass $\left(\mathrm{C}_{29} \mathrm{H}_{40} \mathrm{ClNO}_{2}\right)$. 


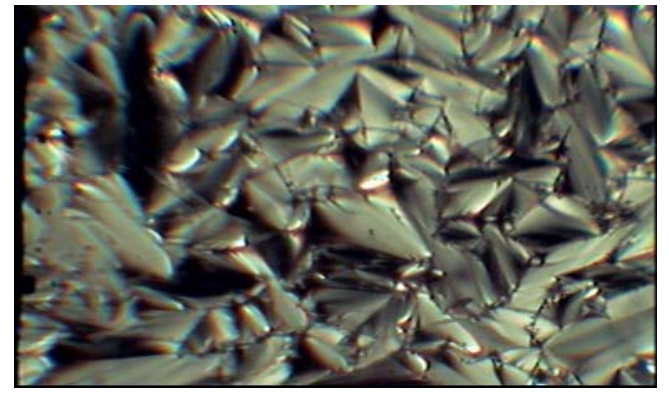

(a)

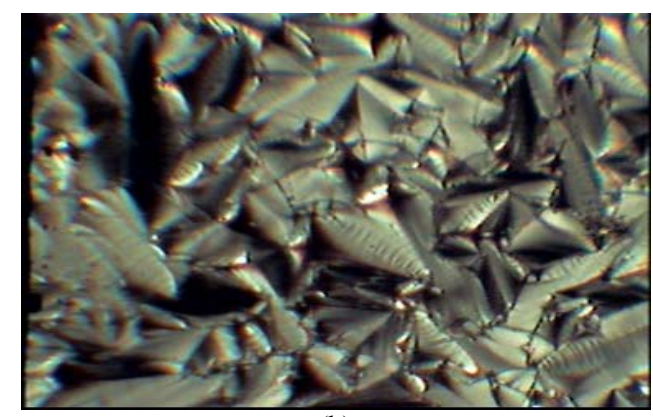

(b)

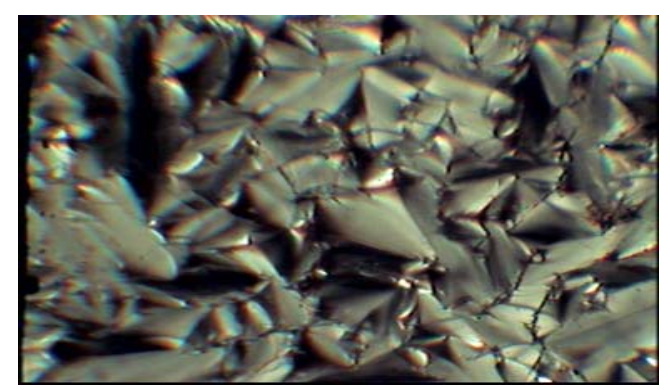

(c)

Fig. 2: Optical photomicrographs of 8ClBA taken during cooling cycle. (a) Optical photomicrograph showing fan-shaped textures of $\mathrm{SmA}$ phase at $92.4^{\circ} \mathrm{C}$; (b) optical photomicrograph exhibiting transition bar at the $\mathrm{SmA}$ to $\mathrm{SmB}$ transition (at $85.2^{\circ} \mathrm{C}$ ); (c) optical photomicrograph displaying mosaic textures of $\mathrm{SmB}$ phase at $78.9^{\circ} \mathrm{C}$

Strong absorption bands appeared at 2917 and $2849 \mathrm{~cm}^{-1}$ in FTIR spectrum of 16ClBA indicates for aliphatic $\mathrm{C}-\mathrm{H}$ in alkyl chain. A medium band at $1749 \mathrm{~cm}^{-1}$ can be ascribed to $\mathrm{C}=\mathrm{O}$ bonds of ester linking group. Absorption band emerged at $1625 \mathrm{~cm}^{-1}$ designates for $\mathrm{C}=\mathrm{N}$ linking group. This value falls within the frequency range reported for Schiff base linkage (Yeap et al., 2004; 2006a; 2006b; 2006c). An absorption band at $1207 \mathrm{~cm}^{-1}$ can be assigned to $\mathrm{C}-\mathrm{O}$ stretching of aromatic ester.

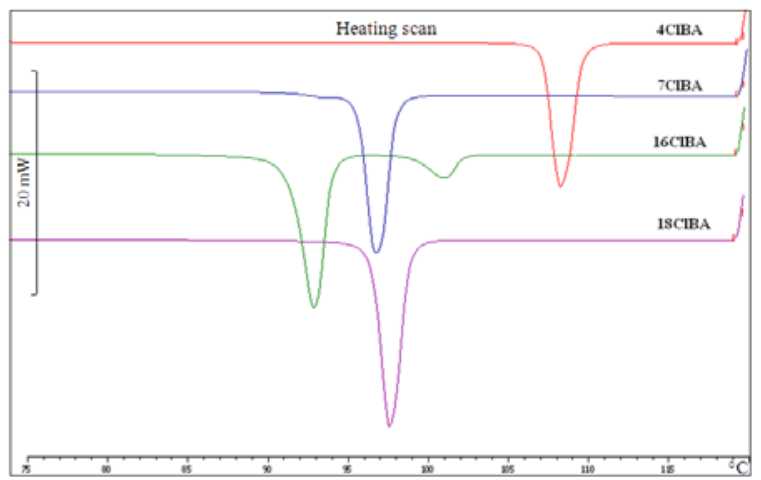

(a)

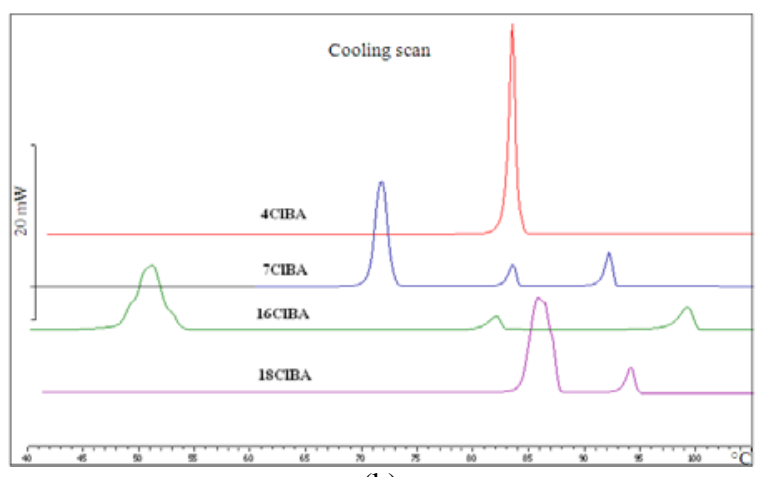

(b)

Fig. 3: DSC thermograms of 4ClBA, 7ClBA, 16ClBA and $18 \mathrm{ClBA}$ during (a) heating and (b) cooling cycles

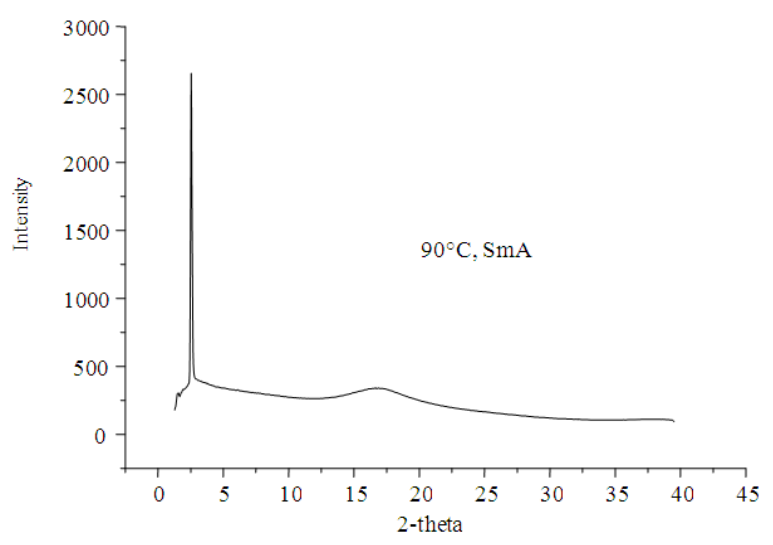

Fig. 4: XRD diffractogram at $90^{\circ} \mathrm{C}$ upon cooling cycle for $12 \mathrm{ClBA}$

In ${ }^{1} \mathrm{H}$ NMR spectrum of $16 \mathrm{ClBA}$, two triplets were observed at $\delta=0.87-0.94 \mathrm{ppm}$ and $\delta=2.56-2.64 \mathrm{ppm}$, which can be ascribed to the methyl and methylene protons $\left(-\mathrm{CH}_{2} \mathrm{COO}-\mathrm{Ar}\right)$. The chemical shifts at $\delta=1.26-$ $1.48 \mathrm{ppm}$ can be assigned to methylene protons of long 
alkyl chain $\left\{-\left(\mathrm{CH}_{2}\right)_{12}-\right\}$. The four distinct double doublets were detected at $\delta=7.10-7.89 \mathrm{ppm}$ can be assigned to aromatic protons. A singlet was observed at the most downfield region, $\delta=8.40 \mathrm{ppm}$ is due to proton of imine linking group (Yeap et al., 2004; $2006 \mathrm{a} ; 2006 \mathrm{~b} ; 2006 \mathrm{c})$. The molecular structure of 16ClBA was further verified by using ${ }^{13} \mathrm{C}$ NMR spectroscopy. A peak at $\delta=14.62 \mathrm{ppm}$ is attributed to the methyl carbon and peaks at $\delta=23.16-34.82 \mathrm{ppm}$ is contributed by the methylene carbons of long alkyl chain. Peaks at $\delta=122.22-149.52 \mathrm{ppm}$ is assigned to twelve aromatic carbons in 16ClBA. The peak at $\delta=159.39 \mathrm{ppm}$ due to existence of azomethine carbon. The most downfield peak in the spectrum, $\delta=172.95$, is ascribed to carbon of ester group.

Phase identification was based on the optical textures and the magnitude of isotropization on enthalpies is consistent with the assignment of each mesophase type, using the classification systems reported Sackmann and Demus (1966) and Gray and Goodby (1984).

Under POM, focal conic fan-shaped textures of smectic A phase was observed during cooling cycle (Fig. 2a). On further cooling, the backs of fan-shaped domains developed a series a dark-lines, which transitory in nature (Fig. 2b) (Singh and Dunmur, 2002; Goodby and Gray, 1979). When further cooling, the bands expand, meet and eventually coalesce to produce polygonal-like texture (Fig. 2c) (Galewski, 1994). This phase is identified as smectic B phase. The similar behavior was also reported for closely-related compound, 4-butyloxybenzylidene-4-chloroaniline (Cozan et al., 2009).

In general, a smectic, nematic and cholesteric structure has a broad peak associated with lateral packing at $2 \theta \approx 16-21^{\circ}$ in a wide-angle XRD curve. A sharp and strong peak at a low angle $\left(1^{\circ}<2 \theta<6^{\circ}\right)$ in a small angle X-ray scattering curve can be observed for smectic structures, but it cannot be seen for nematic and cholesteric structures (Meng et al., 2008). An XRD pattern of 12ClBA showed sharp reflection peaks at $2 \theta$ of $2.55^{\circ}$ at $90^{\circ} \mathrm{C}$, which was corresponding to the smectic layer spacing. The d-layer spacing upon cooling from isotropic liquid to smectic A phase was $30.1 \AA$ whereas the molecular length obtained from MM2 molecular calculation was $27.1 \AA$. Since the calculation of $\mathrm{d} / 1$ ratio to be $1.11(\mathrm{~d} / \mathrm{l}=1)$, the smectic A phase for 12ClBA was suggested to have a monolayer arrangement (Liao et al., 2008). Therefore, it can be deduced that on average the long molecular axis of $12 \mathrm{ClBA}$ in pointing in one favorable direction with a small interaction coefficient.

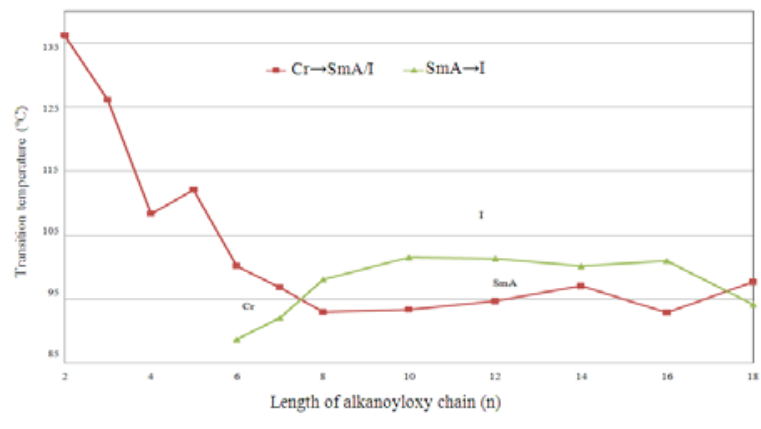

Fig. 5: Plot of transition temperature versus the length of alkanoyloxy chain of nClBA during heating cycle

Influence of alkyl chain length on mesomorphic properties: Representative DSC thermograms expressed the dependence of the transition temperature on the number of carbon at the alkanoyloxy chain for nClAB (where $\mathrm{n}=2,5,6,8$ ) upon heating and cooling is depicted in Fig. 4. A plot of the transition temperatures against the number of carbons in the alkanoyloxy chain during the heating cycle are shown in Fig. 5.

Out of twelve compounds, only four members did not possess mesomorphic properties. They are nethanoyloxy (or C2), n-propanoyloxy (or C3), nbutanoyloxy (or C4) n-pentanoyloxy (or C5) members, therefore, direct crystal-to-isotropic and isotropic-to-crystal transitions were observed during heating and cooling cycles, respectively. This phenomenon could have resulted from the flexibility provided by the carbon chain. Appropriate balance of flexibility and rigidity of a molecule is important for the formation of a mesophase (Collings and Hird, 1997). These molecules (C2-C5 members) with short alkanoyloxy chain are too rigid, having high melting points, thus impeding liquid crystal properties (Kumar, 2001). Once the length of the terminal chain is increased, the molecule becomes more flexible hence promoting a monotropic mesophase in a particular compound. Therefore, C6 and C7 members are monotropic smectogens whereby mesophases (SmA and $\mathrm{SmB}$ ) were only observed during the cooling scan. In the monotropic mesogens, the melting points were always equal to or higher than the clearing points, hence exhibiting supercooling properties (Gray, 1962). Further increasing alkyl chain length from C8-C16 members led to the formation of enantiotropic SmA phase whereby SmA phase was observed during heating and cooling scans. However, SmB phase still remain unchanged as monotropic phase for $\mathrm{C} 8-\mathrm{C} 16$ members. As for the highest member of the series, $\mathrm{C} 18$ 
member, only displayed SmA phase in the cooling cycle. Thus, $\mathrm{C} 18$ is a monotropic SmA mesogen.

Based on the plot (Fig. 5), it can be deduced that the mesophase behaviors were greatly influenced by the length of the terminal chains. High melting point in short chain members normally attributed to the high rigidity of the molecular core (Collings and Hird, 1997). As can be seen in the graph, the shortest chain member, $\mathrm{C} 2$, possessed the highest melting temperature $\left(\mathrm{T}_{\mathrm{m}}=136.2^{\circ} \mathrm{C}\right)$ among the homologues series. The melting point was found to be decreased as the chain length increased to $\mathrm{C} 8$ member $\left(\mathrm{T}_{\mathrm{m}}=93.0^{\circ} \mathrm{C}\right)$ except in $\mathrm{C} 5$ member. This was responded to the increasing flexibility by the longer alkyl chain. It is also common that the melting temperatures showed an ascending trend from medium chain members onwards after a falling trend from short to medium chain members (Kelker and Hatz, 1980). Increasing of melting temperatures was also observed from noctanoyloxy $\left(\mathrm{T}_{\mathrm{m}}=93.0^{\circ} \mathrm{C}\right)$ to n-octadecanoyloxy $\left(\mathrm{T}_{\mathrm{m}}=97.7^{\circ} \mathrm{C}\right)$ except $\mathrm{C} 16$ member. It was probably due to the increasing Van der Waals attractive forces between the molecules (Gray, 1962).

Transition temperatures of SmA-to-I are ascending from C6-C10 members. As from $\mathrm{C} 10-\mathrm{C} 18$ members, the transition temperatures showing falling tendency for SmA-I transition. The terminal intermolecular attractions are playing a part in determining the Sm-I transition temperatures, i.e., the destruction of the smectic molecular order is determined by the fact that the terminal attractions are becoming weaker, allowing partial interpenetration of the layers to occur more easily as the alkanoyloxy chains grow longer, which depress the SmA-to-I transition temperatures (Gray, 1962; Prajapati and Bonde, 2009).

\section{CONCLUSION}

A new homologous series of thermotropic liquid crystal based on Schiff base ester linking group with polar terminal chloro group has been prepared. Mesomorphic properties of these compounds were greatly influenced by the changes of alkyl chain length. The chloro substituent, contributes to molecular polarizability and affecting its intermolecular interactions, leading to smectic polymorphism. Whilst shorter members (C2-C5) are non-mesogenic compounds, n-hexanoyloxy and n-heptanoyloxy exhibited monotropic SmA and SmB phases. Medium (C8-C16) members displayed enantiotropic SmA and monotropic $\mathrm{SmB}$ phases. As for the highest member, C18 member possessed monotropic SmA property.

\section{ACKNOWLEDGEMENT}

The author (S.T. Ha) would like to thank University Tunku Abdul Rahman (UTAR) for the UTAR Research Fund (Vote No. 6200/H02) and the Malaysia Toray Science Foundation (UTAR Vote No. 4359/000) for funding this project. L.K. Ong would like to acknowledge UTAR for the award of the research assistantship. The powder XRD measurements are supported by beamline BL17A (charged by Dr. Jey-Jau Lee) of the National Synchrotron Radiation Research Center, Taiwan.

\section{REFERENCES}

Collings, P.J. and M. Hird, 1997. Introduction to Liquid Crystals Chemistry and Physics. Taylor and Francis Ltd., London, ISBN: 0-7484-0643-3, pp: 298.

Cozan, V., M. Avadanei, E. Perju and D. Timpu, 2009. FTIR investigations of phase transitions in an asymmetric azomethine liquid crystal. Phase Trans., 82 : 607-619. $10.1080 / 01411590903133396$

Dave, J.S. and M. Menon, 2000. Azomesogens with heterocyclic moiety. Bull. Mater. Sci., 23: 237-238. DOI: 10.1007/BF02719917

Galewski, Z., 1994. Liquid crystalline properties of 4halogenobenzyline-4'-alkoxyanilines. Mol. Cryst. Liquid Cryst., 249: 43-49. DOI: $10.1080 / 10587259408038654$

Galewski, Z. and H.J. Coles, 1999. Liquid crystalline properties and phase situations in 4chlorobenzylidene-4'-alkylanilnes. J. Mol. Liquid, 79: 77-87. DOI: 10.1016/S0167-7322(98)00104-4

Goodby, J.W. and G.W. Gray, 1979. Tilted smectic B phase or smectic H phase? J. Phys., 4: 363-370. http://hal.archives-ouvertes.fr/docs/00/21/87/67/PDF/ajpjphyscol197940C371.pdf

Gray, G.W. and J.W. Goodby, 1984. Smectic Liquid Crystals: Textures and Structures. Leonard Hill.

Gray, G.W., 1962. Molecular Structure and Properties of Liquid Crystals. Academic Press, London, ISBN: 978-0122965562, pp: 314.

Ha, S.T., L.K. Ong, S.T. Ong, G.Y. Yeap and J.P.W. Wong et al., 2009a. Synthesis and mesomorphic properties of new Schiff base esters with different alkyl chains. Chin. Chem. Lett., 20: 767-770. DOI: 10.1016/j.cclet.2009.01.011

Ha, S.T., G.Y. Yeap and P.L. Boey, 2009b. Synthesis and liquid crystalline properties of new Schiff bases N-[4-(4-nalkanoyloxybenzoyloxy)benzylidene]-4-cyano-, 4hydroxy-, 4-thio-and 4-nitroanilines. Aust. J. Basic Applied Sci., 3: 3417-3422. http://www.insipub.com/ajbas/2009/3417-3422.pdf 
Kelker, H. and B. Scheurle, 1969. A liquid crystalline (nematic) phase with a particularly low solidification point. Angew. Chem. Int. Edn., 8: 884-885. DOI: 10.1002/anie.196908841

Kelker, H. and R. Hatz, 1980. Handbook of Liquid Crystals. Verlag Chemie, Florida, ISBN: 10: 0895730081 , pp: 917.

Kumar, S., 2001. Liquid Crystals: Experimental Study of Physical Properties and Phase Transitions. Cambridge University Press, Cambridge, ISBN: 0521-46132-4, pp: 483.

Liao, C.C., C.S. Wang, H.S. Sheu and C.K. Lai, 2008. Symmetrical dimer liquid crystals derived from benzoxazoles. Tetrahedron, 64: 7977-7985. DOI: 10.1016/j.tet.2008.06.001

Meng, F.B., Y.M. Gao, J. Lian, B.Y. Zhang and F.Z. Zhang, 2008. Synthesis and characterization of side-chain liquid-crystalline polysiloxanes containing fluorinated units. Colloid Polymer Sci., 286: 873-879. DOI: $10.1007 / \mathrm{s} 00396-007-1829-\mathrm{z}$

Prajapati, A.K. and N.L. Bonde, 2009. Mesogenic benzothiazole derivatives with a polar nitro substituent. Mol. Cryst. Liquid Cryst., 501: 72-85. DOI: $10.1080 / 15421400802697616$

Petrov, V.F., M. Duan, H. Okamoto, J. Mu, Y. Shimizu and S. Takenaka, 2001. Halogenation in achiral liquid crystals: terminal and linking substitutions. Liquid Cryst., 28: 387-410. DOI: 10.1080/02678290010015829

Sackmann, H. and D. Demus, 1966. The polymorphism of liquid crystals. Mol. Cryst. Liquid Cryst., 2: 81-102. DOI: $10.1080 / 15421406608083062$

Sakagami, S. and M. Nakamizo, 1980. Liquid crystalline properties of N-(alkoxybenzylidene) -4halogenoanilines. Bull. Chem. Soc. Jap., 53: 265-266. DOI: $10.1246 / \mathrm{bcsj} .53 .265$
Singh, S. and D.A. Dunmur, 2002. Liquid Crystals: Fundamentals. World Scientific Publishing Co. Pte. Ltd., London, ISBN: 981-02-4250-6, pp: 548. DOI: $10.1142 / 9789812778581$

Yuksel, F., D. Atilla and V. Ahsen, 2007. Synthesis and characterization of liquid crystalline unsymmetrically substituted phthalocyanines. Polyhedron, 26: 4551-4556. DOI: 10.1016/j.poly.2007.06.017

Yeap, G.Y., S.T. Ha, P.L. Lim, P.L. Boey and W.A.K. Mahmood et al., 2004. Synthesis and mesomorphic properties of Schiff base esters ortho-hydroxy-para-alkyloxybenzylidene-parasubstituted anilines. Mol. Cryst. Liquid Cryst., 423: 73-84. DOI: 10.1080/15421400490494508

Yeap, G.Y., S.T. Ha, P.L. Boey, W.A.K. Mahmood and M.M. Ito et al., 2006a. Synthesis and characterization of some new mesogenic Schiff base esters N-[4-(4-nhexadecanoyloxybenzoyloxy)benzylidene]-4substitued anilines. Mol. Cryst. Liquid Cryst., 452: 73-90. DOI: 10.1080/15421400500382156

Yeap, G.Y., S.T. Ha, P.L. Lim, P.L. Boey and M.M. Ito et al., 2006b. Nematic and smectic A phases in ortho-hydroxy-parahexadecanoyloxybenzylidene-para-substituted anilines. Mol. Cryst. Liquid Cryst., 452: 63-72. DOI: 10.1080/15421400500377750

Yeap, G.Y., S.T. Ha, P.L. Boey, M.M. Ito and S. Sanehisa et al., 2006c. Synthesis, physical and mesomorphic properties of schiff base esters containing ortho-,meta- and para-substituents in benzylidene-4'-alkanoyloxyanilines. Liquid Cryst., 33: 205-211. DOI: $10.1080 / 02678290500450584$

Zhang, B.Y., F.B. Meng, M. Tian and W.Q. Xiao, 2005. Side-chain liquid-crystalline polysiloxanes containing ionic mesogens and cholesterol ester groups. React. Funct. Polymer, 66: 551-558. DOI: 10.1016/j.reactfunctpolym.2005.10.030 